\title{
Deposição de Glyphosate Aplicado para Controle de Plantas Daninhas EM SoJa TRANSGÊNiCA ${ }^{1}$
}

\author{
Glyphosate Deposition for Weed Control in Transgenic Soybean \\ GAZZIERO, D.L.P. ${ }^{2}$, MACIEL, C.D.G. ${ }^{3}$, SOUZA, R.T. ${ }^{3}$, VELINI, E.D. ${ }^{4}$, PRETE, C.E.C. ${ }^{5}$ e
OLIVEIRA NETO, W. ${ }^{6}$
}

\begin{abstract}
RESUMO - Inúmeros fatores estão envolvidos na tecnologia de aplicação de um herbicida, sendo a deposição correta fundamental para que o produto possa expressar sua eficiência. Com o objetivo de avaliar a deposição de uma solução traçante constituída de glyphosate Roundup Ready (0,96 kg e.a. ha-1) + corante FDC-1 (1.500 ppm), foi conduzido um experimento em área semeada com soja transgênica e infestada com amendoim-bravo (Euphorbia heterophylla), localizada em Londrina-PR. As aplicações foram efetuadas em diferentes estádios de desenvolvimento da cultura, correspondendo a 17, 24, 31, 38 e 45 dias após a emergência da soja. Os alvos, plantas de soja, amendoim-bravo e placas na superfície do solo (linha e entrelinha), foram coletados após pulverização, e a solução traçante foi nestes depositada, posteriormente recuperada através de lavagem com agitação em água destilada. As amostras das soluções recuperadas foram submetidas à análise, utilizando-se procedimentos espectrofotométricos, e os resultados de absorbância convertidos para concentração em $\mu \mathrm{L} \mathrm{cm}^{-2} \mathrm{e} \mu \mathrm{L}$ por planta. As freqüências acumuladas dos dados originais de depósito foram adequadamente ajustadas segundo modelo de Gompertz, apresentando elevada precisão $\left(\mathrm{R}^{2}>0,95\right)$. Os resultados indicaram que o depósito da calda de pulverização nas plantas de soja e amendoim-bravo reduziu progressivamente com o desenvolvimento da cultura e infestação, sugerindo que a maior garantia de eficiência de controle pode ser conseguida com aplicações precoces.
\end{abstract}

Palavras-chave: Roundup Ready, traçante (Blue Brilhant) e soja transgênica.

ABSTRACT - Several factors are involved in herbicide application technology, with correct deposition being essential to ensure product efficacy. To evaluate the deposition of a glyphosate tracer solution (RR) with an FDC-1 dye, an experiment was carried out in a transgenic soybean cultivated area, infested with wild poinsettia (Euphorbia heterophylla). Applications were carried out at different crop development stages, corresponding to 17;24; 1 ; 38 and 45 days after soybean emergence. The targets, soybean plants, wild poinsettias, and Petri dishes on the soil surface, were collected after spraying and the tracer solution was later recovered by washing and stirring in distilled water. Samples of recovered solutions were submitted to spectrophotometer analysis, and the absorption data were converted in $\mu \mathrm{L} \mathrm{cm}^{-2}$ and $\mu \mathrm{L}$ per plant. The accumulated frequencies of the original deposit data were adequately adjusted to the Gompertz model, showing high precision $\left(R^{2}\right.$ $>$ 0.95). The results showed that the spraying solution deposition on soybean plants and wild poinsettia reduced progressively with crop development and weed infestation, suggesting that control efficiency can be obtained with early applications.

Keywords: Roundup Ready, tracer (Brilliant Blue), and transgenic soybean.

1 Recebido para publicação em 25.10.2004 e na forma revisada em 24.2.2006.

2 Eng.-Agr. D.S., Pesquisador da Embrapa Soja, Caixa Postal 231, 86001-970 Londrina-PR, <gazziero@ @npso.embrapa.br>. ${ }^{3}$ Eng.-Agr. Doutorando, Universidade Estadual Paulista - UNESP, 18603-970 Botucatu-SP, <maciel@fca.unesp.br>, recco@ univag.com.br>; ${ }^{4}$ Eng.-Agr. D.S., Professor da UNESP, Botucatu-SP, <velini@ fca.unesp.br>. ${ }^{5}$ Eng.-Agr. D.S., Professor da Universidade Estadual de Londrina - UEL, 86051-990 Londrina-PR, <cassio@uel.br>. ${ }^{6}$ Técnico de Laboratório da Embrapa Soja, M.S., <waldemar@cnpso.embrapa.br>. 


\section{INTRODUÇÃO}

O crescimento, o desenvolvimento e a produtividade da soja são influenciados por diversos fatores. Entre os mais importantes encontra-se a interferência causada pelas planta daninhas.

Existe um período, que se inicia na emergência, no qual a cultura pode conviver com a comunidade infestante sem que sua produtividade ou outras características sejam alteradas (Pitelli \& Durigan, 1984). O período anterior à interferência (PAI) situa-se entre 20 e 35 dias após a emergência da cultura (Pitelli, 1985). Entretanto, segundo alguns trabalhos, esse período de dias pode variar em função da maior ou menor disponibilidade de elementos básicos, como luz, água e nutrientes, assim como da comunidade, da pressão de infestação e das condições em que a convivência ocorre (Blanco et al., 1973, 1979; Carvalho \& Velini, 2001).

Para controlar as plantas daninhas, praticamente todas as áreas de produção comercial utilizam herbicidas. Na soja transgênica não é diferente, embora o produto a ser utilizado seja apenas um: o glyphosate. Com essa tecnologia, existe a possibilidade de ocorrência de grandes mudanças em conceitos e atitudes, mas a essência do manejo integrado deve ser preservada, sob pena de serem colocados em risco os avanços obtidos (Gazziero, 2001).

O glyphosate é um herbicida sistêmico utilizado em pós-emergência no controle de gramineas e de folhas largas (Rodrigues \& Almeida, 1998). Na soja transgênica é utilizado em aplicações únicas ou seqüenciais, em doses e épocas que irão variar conforme cada cenário. Para trapoeraba (Commelina benghalensis), uma espécie considerada tolerante ao glyphosate, resultados aceitáveis de controle foram obtidos para aplicações precoces e seqüenciais desse produto em baixas doses, comparativamente melhores do que as aplicações mais tardias e em doses mais elevadas (Gazziero et al., 1998).

Quando se aplica um herbicida após a emergência de uma cultura qualquer, apenas parte da calda pulverizada atinge o alvo desejado. Dessa forma, para essa modalidade de aplicação a deposição atinge a cultura, as plantas daninhas e possivelmente o solo. A proporção nos referidos alvos irá variar com a época de aplicação; quando não se utiliza tecnologia adequada, parte do produto pode ainda se perder por deriva no ambiente. Além disso, um tratamento fitossanitário tem seu sucesso associado a uma série de fatores, nos quais eficácia do composto químico e tecnologia de aplicação estão diretamente envolvidas com aspectos meteorológicos, biológicos e agronômicos. Lima \& Machado Neto (2001) verificaram ser possível otimizar o uso de fluazifop-p-butil em função do horário de aplicação com redução de doses e volume de calda. Resultados semelhantes foram obtidos por Gazziero (1980) com herbicidas utilizados no controle pós-emergente de espécies de folha larga em soja. O êxito depende ainda da época e tamanho da invasora, da cobertura, da dose correta e da segurança (Ozeki \& Kunz, 1998).

Ao estudar o efeito da eletrização de gotas sobre a variabilidade dos depósitos de pulverização e eficácia de glyphosate, Souza (2002) concluiu que a irregularidade pode levar à necessidade de aumento da dose aplicada e que a proximidade das plantas daninhas com a cultura desuniformiza e reduz os depósitos da calda de aplicação. Maciel et al. (2001) avaliaram a deposição e distribuição de solução traçante em plantas de feijoeiro e capimbraquiária, verificando que a associação do surfatante à calda de pulverização alterou com vantagens para cultura a relação de depósitos. Os autores constataram ainda aumentos significativos na deposição e distribuição da aplicação em plantas daninhas em função da ponta de pulverização utilizada. Furlanetti et al. (2001), estudando a uniformidade de distribuição da calda de pulverização de herbicidas em culturas perenes arbustivas, relataram que existem combinações ideais de pontas de pulverização, com volumes de calda e velocidade de deslocamento, os quais podem ser ajustados por programa em computador.

O presente trabalho teve por objetivo avaliar a deposição de glyphosate aplicado em uma área semeada com soja transgênica infestada com plantas de amendoim-bravo (Euphorbia heterophylla). 


\section{MATERIAL E MÉTODOS}

O experimento foi conduzido em área de campo da Embrapa Soja, no delineamento experimental de blocos casualizados com quatro repetições. O glyphosate foi aplicado na dose de 0,96 kg ha-1 do e.a. (Roundup Ready) em seis diferentes épocas, correspondente a 17 (V3), 24 (V5), 31 (V6), 38 (V7) e 45 (V8) dias após a emergência da cultura (DAE). Utilizouse a soja transgênica, linhagem BR 99-27869, semeada em 10/11/2001, em parcelas de $16 \mathrm{~m}^{2}$ infestadas com plantas de amendoimbravo em densidade média de 50 plantas $\mathrm{m}^{-2}$.

As aplicações foram todas realizadas pela manhã, estando as condições climáticas sempre dentro dos padrões recomendados, com pulverizador costal de precisão equipado com pontas XR 110-015, pressão de $30 \mathrm{Lb} \mathrm{pol}^{-2} \mathrm{e}$ volume de calda de $150 \mathrm{~L} \mathrm{ha}^{-1}$. Foram adicionados à calda 1.500 ppm do corante azul FDC-1 (Blue Brilhant), para atuar como traçante e permitir os procedimentos cromatográficos conforme Maciel (2001).

Em cada época após aplicação, foram coletadas 100 amostras de plantas de soja, 70 amostras de amendoim-bravo e 26 tampas de gerbox distribuídas previamente nas linhas e entrelinhas da cultura da soja, representando as repetições para os respectivos alvos. As tampas de gerbox foram utilizadas para receptar o depósito da calda de pulverização que atinge o solo. Foi considerado como linha o espaço de $12 \mathrm{~cm}$, representado pela área de $6 \mathrm{~cm}$ de cada lado da planta de soja, e como entrelinha a região central entre as linhas da cultura.

As amostras coletadas logo após a pulverização foram armazenadas em sacos plásticos e levadas ao laboratório, onde foram lavadas com água destilada, utilizando-se $25 \mathrm{~mL}$ para extração do corante das plantas daninhas e $40 \mathrm{~mL}$ para as plantas de soja e tampas de gerbox. Para padronização da extração da solução traçante estabeleceu-se uma rotina de lavagem, constituída pela agitação manual da água + alvo dentro do saco plástico, por um período de aproximadamente 15 segundos. A determinação da quantidade de traçante depositada foi efetuada utilizando-se espectrofotômetro, cujos resultados da leitura em absorbância no comprimento de onda de
$630 \mathrm{~nm}$ proporcionaram a transformação em $\mathrm{mg} \mathrm{L}^{-1}$ de acordo com coeficiente angular da curva-padrão. Os valores de depósito foram posteriormente transformados $\mathrm{em} \mathrm{mL} \mathrm{cm}{ }^{-2} \mathrm{e}$ $\mathrm{mL}$ por planta, conforme metodologia descrita por Palladini (2000) e Souza (2002).

Os dados obtidos dos depósitos em porcentagem foram ajustados pelo modelo de Gompertz $\left(\mathrm{F}=\mathrm{e}^{\wedge}\left(\mathrm{a}-\mathrm{e}^{\wedge}\left(-\mathrm{b} \mathrm{c}^{*} \mathrm{X}\right)\right)\right)$, para representar a freqüência acumulada $(\mathrm{F})$ da deposição da calda pulverizada em percentagem. Adotou-se o valor de 4,60517 para o parâmetro "a" do modelo, o qual representa a assintota máxima da curva, em que "e $\mathrm{e}^{\mathrm{a}}=100$, conforme modelo ajustado por Velini (1995). O deslocamento da curva ao longo do eixo x é representado pelo módulo do parâmetro "a", e a inclinação ou concavidade da curva em relação à freqüência acumulada, pelo parâmetro "c". Além disso, para melhor visualização, optou-se por apresentar as freqüências não-acumuladas $\left(\mathrm{FN}=\mathrm{c}^{*} \mathrm{e}^{\wedge}\left(\mathrm{a}-\mathrm{b}-\mathrm{c}{ }^{*} \mathrm{X}-\right.\right.$ $\left.\left.\mathrm{e}^{\wedge}\left(-\mathrm{b}-\mathrm{c}^{*} \mathrm{X}\right)\right)\right)$, que correspondem à derivada da primeira do modelo. As freqüências acumuladas e não-acumuladas do modelo de Gompertz permitem a interpretação biológica dos resultados. Para facilitar a visualização das informações, a derivada da primeira corresponde à moda da deposição da solução pulverizada nos alvos específicos (Velini, 1995).

Os valores de média, moda e mediana também foram estabelecidos no trabalho. A precisão do ajuste dos dados do modelo de Gompertz foi avaliada por meio dos coeficientes de determinação $\left(\mathrm{R}^{2}\right)$ e pelas somas dos quadrados de resíduos das equações.

\section{RESULTADOS E DISCUSSÃO}

Nas Figuras 1 e 2 são apresentados os dados originais e as freqüências acumuladas e não-acumuladas em função do depósito da solução traçante FDC-1 + glyphosate em plantas de soja. Os resultados das análises de regressão, assim como as estimativas dos parâmetros do modelo de Gompertz, são apresentados nas Tabelas 1 e 2 para os alvos soja e amendoim-bravo. Por meio dos dados originais, constatou-se que as relações entre o maior e o menor depósito foram de aproximadamente 6,$5 ; 8,2 ; 8,3 ; 26,1$; e 12,2 vezes para a soja $\left(\mathrm{mL} \mathrm{cm}^{-2}\right)$ e 35,$2 ; 4,3$; e 7,4 vezes para o 
amendoim-bravo $\left(\mathrm{mL} \mathrm{cm}^{-2}\right)$, nas respectivas épocas de aplicação correspondentes a 17, 24, 31,38 e 45 DAE para soja e 17, 24 e 31 DAE para amendoim-bravo. A variação da deposição possivelmente está relacionada com a diferença de tamanho e o estádio de desenvolvimento dos alvos, sugerindo uma tendência de maiores irregularidades em períodos diferenciados.

Na Figura 1 e Tabela 1, observa-se ainda que a deposição da solução traçante reduziu progressivamente nas plantas de soja ao longo do desenvolvimento da cultura. No entanto,
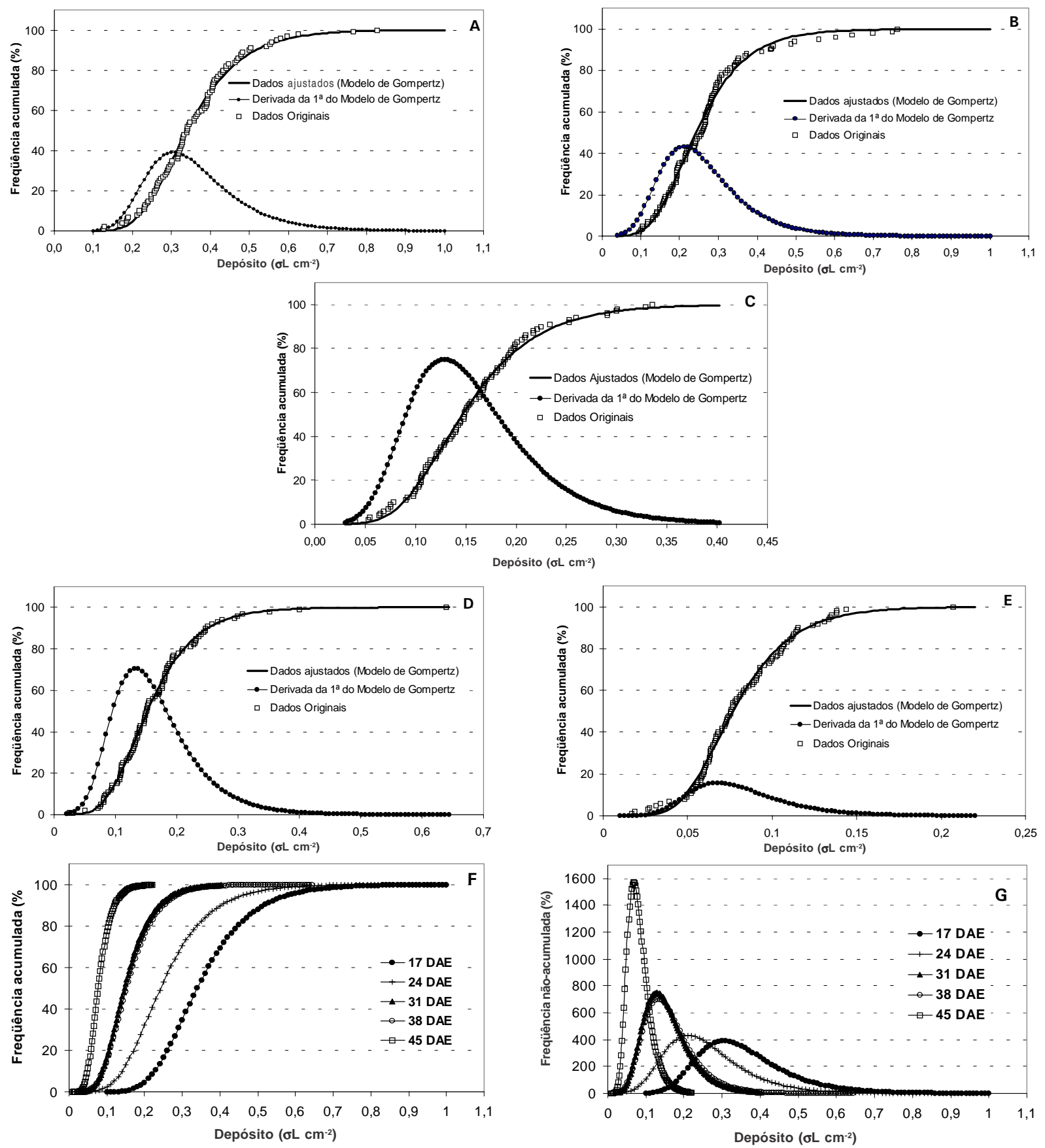

Figura 1 - Representação das freqüências acumuladas (\%) e não-acumuladas da população de plantas de soja amostrada aos 17 (A), 24 (B), 31 (C), 38 (D) e 45 dias após emergência (DAE) (E) e análises gerais (F e G) em função do volume da solução FDC-1 + glyphosate depositada por unidade de área foliar, utilizando-se o modelo de Gompertz. 
através dos valores de freqüências acumuladas e não-acumuladas dispostas na Figura $2 \mathrm{~F}$ e $\mathrm{G}$ e Tabela 2, pode-se confirmar essa afirmativa, uma vez que as plantas menores apresentaram maior uniformidade de depósito da calda pulverizada por unidade de planta, condição associada à maior concavidade (menor curtose) das curvas de freqüências não-acumuladas e/ou aos maiores valores do parâmetro "C" do modelo de Gompertz para as primeiras avaliações desenvolvidas no trabalho. Dessa forma, os dados ajustados
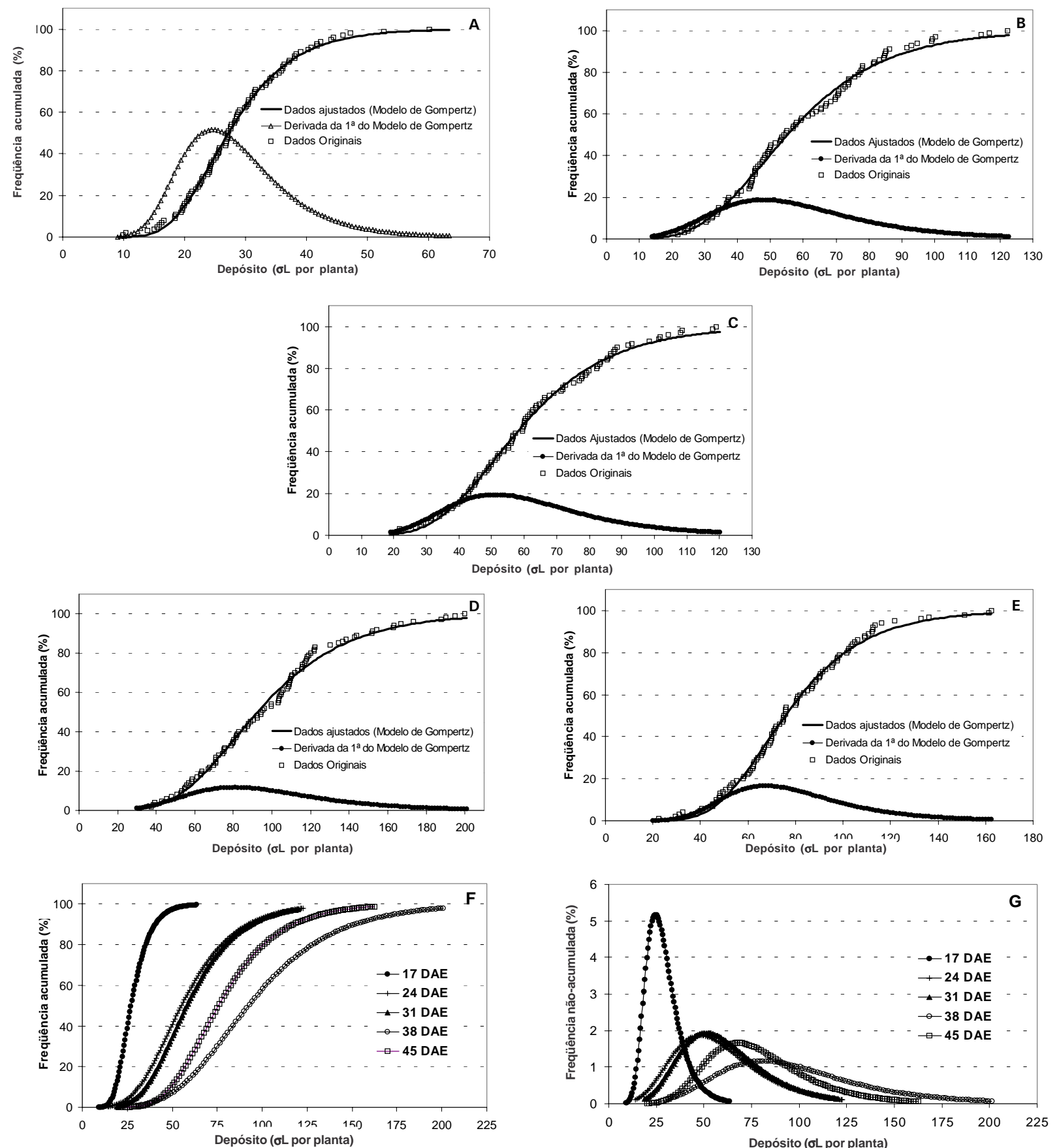

Figura 2 - Representação das frequiências acumuladas (\%) e não-acumuladas da população de plantas de soja amostrada aos 17 (A), 24 (B), 31 (C), 38 (D) e 45 dias após emergência (DAE) (E) e análises gerais (F e G) em função do volume da solução FDC-1 + glyphosate depositada por unidade de planta, utilizando-se o modelo de Gompertz. 
permitem inferir que, quanto menor a planta de soja, maior será a retenção de glyphosate pela parte área da cultura. Resultados semelhantes foram encontrados por Souza (2002) tanto em pulverização convencional como em eletrostática e por Tomazella (1997) utilizando Brachiaria plantaginea.
Ainda na Tabela 2, podem-se constatar os valores modais representados pela maior freqüência de valores nas equações de freqüências não-acumuladas do modelo de Gompertz (Figura 2G), os quais variaram de 24,58 a $80,95 \mathrm{~mL}$ por planta para as diferentes épocas de aplicação.

Tabela 1 - Resultados das análises de regressão entre as frequiências acumuladas e os volumes de depósito da solução pulverizada, utilizando o modelo de Gompertz, médias, modas e medianas da deposição em plantas de soja e amendoimbravo, em diferentes épocas de aplicação. UEL, Londrina-PR, 2003

\begin{tabular}{|c|c|c|c|c|c|c|c|c|c|}
\hline \multirow{3}{*}{\multicolumn{2}{|c|}{ Modelo }} & \multicolumn{8}{|c|}{ Frequiência acumulada $(\%)=\mathrm{e}^{\wedge}\left(\mathrm{a}-\mathrm{e}^{\wedge}\left(-\mathrm{b}-\mathrm{c}^{*} \mathrm{X}\right)\right)$} \\
\hline & & \multicolumn{5}{|c|}{ Soja $\left(P L \mathrm{~cm}^{-2}\right)$} & \multicolumn{3}{|c|}{ Amendoim-bravo $\left(\mathrm{PL} \mathrm{cm} \mathrm{cm}^{-2}\right)$} \\
\hline & & 17 DAE & $24 \mathrm{DAE}$ & $31 \mathrm{DAE}$ & $38 \mathrm{DAE}$ & $45 \mathrm{DAE}$ & $17 \mathrm{DAE}$ & $24 \mathrm{DAE}$ & $31 \mathrm{DAE}$ \\
\hline \multirow{3}{*}{$\begin{array}{l}\text { Estimativa dos } \\
\text { parâmetros }\end{array}$} & A & 4,60517 & 4,60517 & 4,60517 & 4,60517 & 4,60517 & 4,60517 & 4,60517 & 4,60517 \\
\hline & $\mathrm{B}$ & $-3,24629$ & $-2,48408$ & $-2,62487$ & $-2,55369$ & $-2,91229$ & $-2,45668$ & $-2,76478$ & $-2,44277$ \\
\hline & $\mathrm{C}$ & 10,63406 & 11,76569 & 20,37810 & 19,17530 & 42,72896 & 9,68423 & 19,92140 & 20,69737 \\
\hline F Regressão & & $168987,41^{* *}$ & $163803,434 * *$ & $164015,645 * *$ & $164047,153 * *$ & $163939,712 * *$ & $119030,649 * *$ & $114061,851 * *$ & $114074,955^{*}$ \\
\hline S Q Resíduo & & 375,1815 & 743,1321 & 318,7114 & 255,6938 & 470,5636 & 295,8450 & 232,871 & 206,661 \\
\hline $\mathrm{R}^{2}$ & & 0,9954 & 0,9908 & 0,9960 & 0,9968 & 0,9942 & 0,9949 & 0,9958 & 0,9963 \\
\hline $\mathrm{N}^{\mathrm{o}}$ de repetições & & 100 & 100 & 100 & 100 & 100 & 70 & 70 & 70 \\
\hline Média & & 0,35776 & 0,27002 & 0,15592 & 0,16697 & 0,08122 & 0,32312 & 0,16731 & 0,16921 \\
\hline Moda & & 0,30527 & 0,21113 & 0,12881 & 0,13318 & 0,06816 & 0,25368 & 0,13878 & 0,11802 \\
\hline Mediana & & 0,33974 & 0,24228 & 0,14679 & 0,15229 & 0,07673 & 0,29152 & 0,15718 & 0,13573 \\
\hline
\end{tabular}

** Significativo a $1 \%$ de probabilidade.

DAE = Dias Após a Emergência da cultura da soja; X = quantidade de calda de FDC-1 + glyphosate depositada em plantas de soja e amendoimbravo $\left(\mathrm{PL} \mathrm{cm}{ }^{-2}\right) ; \mathrm{A}, \mathrm{B}$ e C são as estimativas dos parâmetros do modelo.

Tabela 2 - Resultados das análises de regressão entre as freqüências acumuladas e os volumes de depósito da solução pulverizada, utilizando o modelo de Gompertz, médias, modas e medianas da deposição em plantas de soja e amendoimbravo, em diferentes épocas de aplicação. UEL, Londrina-PR, 2003

\begin{tabular}{|c|c|c|c|c|c|c|c|c|}
\hline \multirow{3}{*}{ Modelo } & \multicolumn{8}{|c|}{ Freqüência acumulada $(\%)=\mathrm{e}^{\wedge}\left(\mathrm{a}-\mathrm{e}^{\wedge}\left(-\mathrm{b}-\mathrm{c}^{*} \mathrm{X}\right)\right)$} \\
\hline & \multicolumn{5}{|c|}{ Soja (PLpor planta) } & \multicolumn{3}{|c|}{ Amendoim-bravo (PL por planta) } \\
\hline & 17 DAE & $24 \mathrm{DAE}$ & $31 \mathrm{DAE}$ & $38 \mathrm{DAE}$ & $45 \mathrm{DAE}$ & $17 \mathrm{DAE}$ & $24 \mathrm{DAE}$ & $31 \mathrm{DAE}$ \\
\hline \multirow{3}{*}{$\begin{array}{l}\text { Estimativa dos } \\
\text { parâmetros }\end{array}$} & 4,60517 & 4,60517 & 4,60517 & 4,60517 & 4,60517 & 4,60517 & 4,60517 & 4,60517 \\
\hline & $-3,45082$ & $-2,42732$ & $-2,69626$ & $-2,56778$ & $-3,05794$ & $-1,34431$ & $-2,43414$ & $-1,30755$ \\
\hline & 0,14040 & 0,05066 & 0,05265 & 0,03172 & 0,04524 & 1,03209 & 0,28950 & 0,24029 \\
\hline F Regressão & $169071,254^{* *}$ & $168932,053 * *$ & $169065,014 * *$ & $168906,542 * *$ & $168989,442 * *$ & $118609,666^{* * *}$ & $118949,381^{* * *}$ & $118936,292^{* * *}$ \\
\hline S Q Resíduo & 207,492 & 485,895 & 219,972 & 536,916 & 371,114 & 1137,238 & 458,382 & 484,558 \\
\hline $\mathrm{R}^{2}$ & 0,9975 & 0,9942 & 0,9974 & 0,9935 & 0,9954 & 0,9805 & 0,9921 & 0,9917 \\
\hline $\mathrm{N}^{\mathrm{o}}$ de repetições & 100 & 100 & 100 & 100 & 100 & 70 & 70 & 70 \\
\hline Média & 28,47504 & 58,58230 & 61,47283 & 97,97471 & 79,30014 & 2,00395 & 10,67153 & 8,66131 \\
\hline Moda & 24,57849 & 47,91394 & 51,21100 & 80,95136 & 67,59073 & 1,30251 & 8,40818 & 5,44156 \\
\hline Mediana & 27,18889 & 55,14844 & 58,17206 & 92,50558 & 75,69161 & 1,65762 & 9,67417 & 6,96680 \\
\hline
\end{tabular}

** Significativo a $1 \%$ de probabilidade.

DAE = Dias Após a Emergência da cultura da soja; $\mathrm{X}$ = quantidade de calda de FDC-1 + glyphosate depositada em plantas de soja e amendoimbravo (PL por planta); A, B e C são as estimativas dos parâmetros do modelo. 
Para a planta daninha amendoim-bravo (Figura 3A e B), a deposição da solução FDC-1 + glyphosate apresentou comportamento similar ao da soja, constituindo-se por redução progressiva de sua concentração por unidade de área foliar com o desenvolvimento da cultura e/ou época de avaliação. Entretanto, na Tabela 1 as diferenças da concentração depositada na infestação entre os períodos de 24 e 31 DAE $\left(0,14\right.$ e $\left.0,12 \mathrm{~mL} \mathrm{~cm}^{-2}\right)$ foram menos evidentes quando comparadas às da primeira avaliação, desenvolvida aos $17 \mathrm{DAE}$ $\left(0,25 \mathrm{~mL} \mathrm{~cm}^{-2}\right)$. Para concentração da solução por unidade de planta (mL por planta), representada pelos valores de média, moda e mediana na Tabela 2, pode-se constatar respectiva alternância da concentração nas avaliações de 24 e 31 DAE. Maior deposição na soja significa maior absorção e necessidade de energia para metabolização do produto, enquanto para planta daninha significa possibilidade de melhor eficiência no controle, já que ocorre maior concentração de herbicida por unidade de área foliar.

Os dados de deposição da solução traçante amostrados na superfície do solo encontramse dispostos na Figura 4 e Tabela 3. Para essa variável, constatou-se evidente redução progressiva da concentração da solução traçante que atingiu o solo nas posições da linha e entrelinha com o desenvolvimento da cultura. A quantidade depositada na avaliação de 18 DAE foi proporcionalmente semelhante tanto na linha como na entrelinha. Entre a segunda e a quarta aplicação (27 a 41 DAE), o gerbox da linha recebeu praticamente a metade da quantidade verificada na entrelinha, indicando que, quanto mais próximas da soja estiverem as plantas daninhas, maior a dificuldade para se atingir o alvo. Qualquer produto fitossanitário deve atingir o alvo para exercer sua ação - caso contrário, seu uso pode não ser justificado (Matuo, 1998).

Por ocasião dos $45 \mathrm{DAE}$, tanto a cultura como as plantas daninhas apresentavam-se bastante desenvolvidas e a deposição voltou a ser semelhante para as duas situações estudadas, o que justifica ter havido efeito de sobreposição causado pelas folhas de soja e de amendoim-bravo. Segundo Ozeki \& Kunz (1998), o momento oportuno para realizar a aplicação é um dos fatores considerados fundamentais para se obter êxito pleno na operação de controle. Dessa forma, a redução na
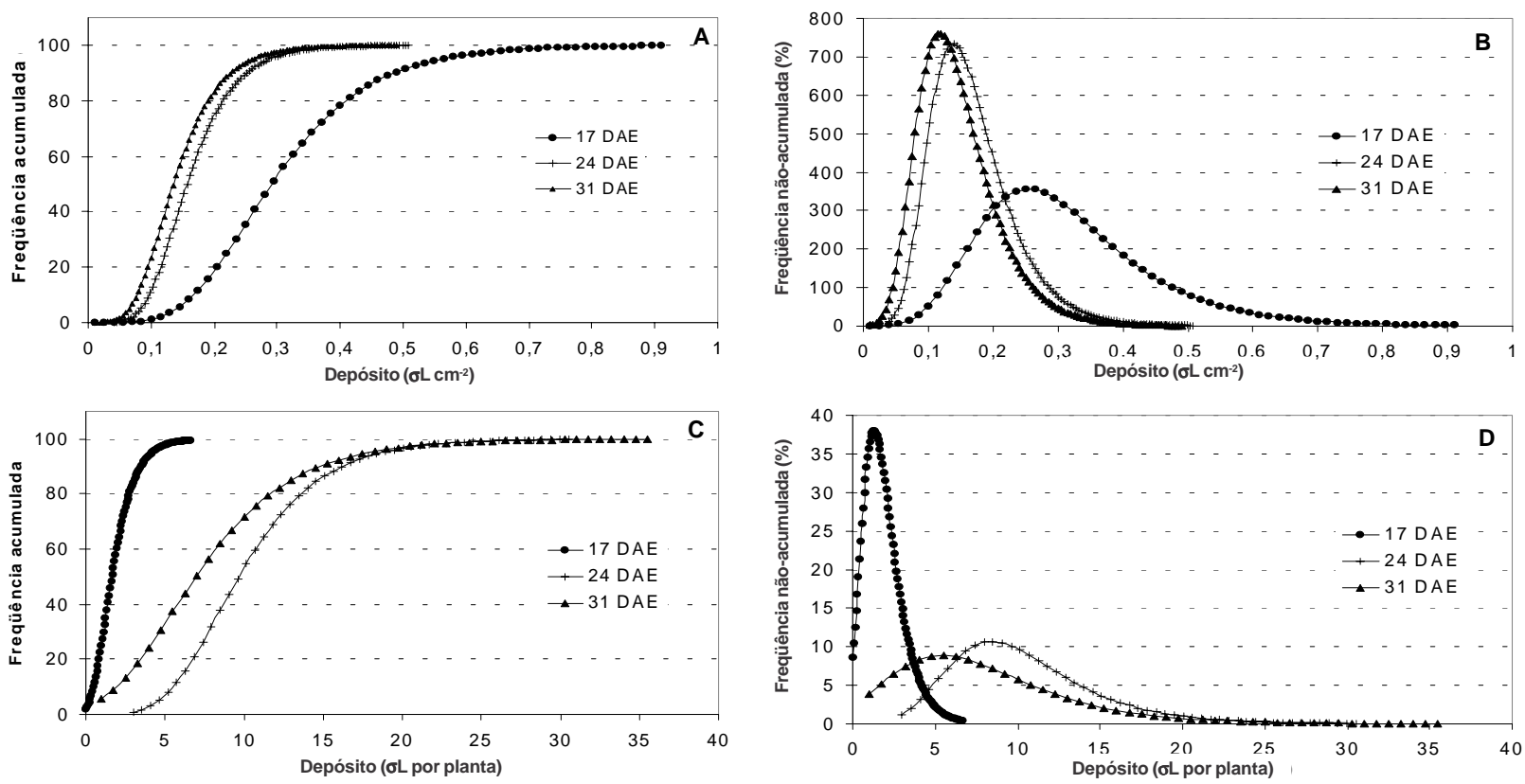

Figura 3 - Freqüências acumuladas (\%) e não-acumuladas da população de plantas de amendoim-bravo amostrada aos 17, 24 e 31 dias após emergência (DAE) em função do volume da solução FDC-1 + glyphosate depositada por unidade de área foliar (A e B) e de planta (C e D), utilizando-se o modelo de Gompertz. 

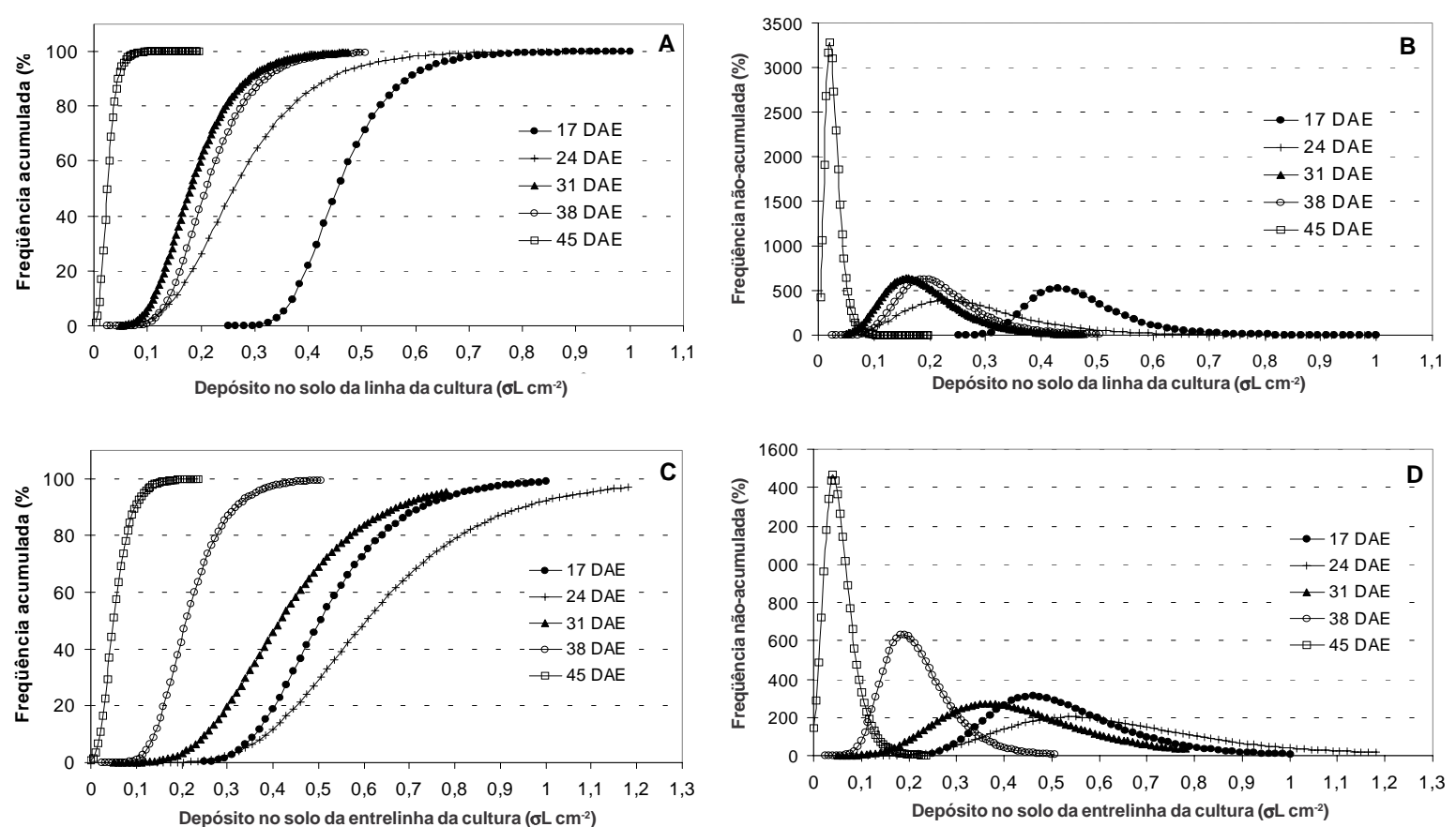

Figura 4 - Freqüências acumuladas (\%) e não-acumuladas das tampas de gerbox amostradas aos 17, 24, 31,38 e 45 dias após emergência (DAE) em função do volume da solução FDC-1 + glyphosate depositada por unidade de área na linha (A e B) e entrelinha (C e D), utilizando-se o modelo de Gompertz.

Tabela 3 - Resultados das análises de regressão entre as freqüências acumuladas e os volumes de depósito da solução pulverizada, utilizando o modelo de Gompertz, médias, modas e medianas da deposição no solo das linhas e entrelinhas da soja, em diferentes épocas de aplicação. UEL, Londrina-PR, 2003

\begin{tabular}{|c|c|c|c|c|c|c|c|c|c|c|c|}
\hline \multirow{3}{*}{ Modelo } & & \multicolumn{10}{|c|}{ Freqüência acumulada $(\%)=\mathrm{e}^{\wedge}\left(\mathrm{a}-\mathrm{e}^{\wedge}\left(-\mathrm{b}-\mathrm{c}^{*} \mathrm{X}\right)\right)$} \\
\hline & & \multicolumn{5}{|c|}{ linha $\left(P L \mathrm{~cm}^{-2}\right)$} & \multicolumn{5}{|c|}{ entrelinha $\left(\mathrm{PL} \mathrm{cm} \mathrm{cm}^{-2}\right)$} \\
\hline & & 17 DAE & $24 \mathrm{DAE}$ & $31 \mathrm{DAE}$ & 38 DAE & 45 DAE & 17 DAE & 24 DAE & 31 DAE & 17 DAE & $24 \mathrm{DAE}$ \\
\hline \multirow{3}{*}{$\begin{array}{l}\text { Estimativa dos } \\
\text { parâmetros }\end{array}$} & $\bar{A}$ & 4,60517 & 4,60517 & 4,60517 & 4,60517 & 4,60517 & 4,60517 & 4,60517 & 4,60517 & 4,60517 & 4,60517 \\
\hline & B & $-6,16221$ & $-2,43950$ & $-2,75437$ & $-1,27960$ & $-1,87304$ & $-3,88349$ & $-2,95418$ & $-2,69818$ & $-3,24494$ & $-1,62999$ \\
\hline & $\mathrm{C}$ & 14,36130 & 10,71175 & 17,28435 & 18,67889 & 89,38818 & 8,44136 & 5,48926 & 7,37344 & 17,21859 & 39,81389 \\
\hline \multicolumn{2}{|l|}{ F Regressão } & 45735,37 ** & $40718,73 * *$ & $40691,28 * *$ & $4064929 * *$ & $40675,79 * *$ & $45562,61 * *$ & $40668,50 * *$ & $40388,29 * *$ & $40573,52^{* *}$ & $40668,51 * *$ \\
\hline \multicolumn{2}{|l|}{ S Q Resíduo } & 260,021 & 293,153 & 348,060 & 432,041 & 379,039 & 605,547 & 393,605 & 954,035 & 583,777 & 393,605 \\
\hline \multicolumn{2}{|l|}{$\mathrm{R}^{2}$} & 0,9880 & 0,9848 & 0,9842 & 0,9775 & 0,9803 & 0,9720 & 0,9795 & 0,9504 & 0,9696 & 0,9516 \\
\hline \multicolumn{2}{|l|}{$\mathrm{N}^{\underline{o}}$ de repetições } & 26 & 26 & 26 & 26 & 26 & 26 & 26 & 26 & 26 & 26 \\
\hline \multicolumn{2}{|l|}{ Média } & 0,49008 & 0,29829 & 0,19151 & 0,10809 & 0,03636 & 0,53688 & 0,64708 & 0,42747 & 0,2279 & 0,06911 \\
\hline \multicolumn{2}{|l|}{ Moda } & 0,42908 & 0,22774 & 0,15936 & 0,06850 & 0,02095 & 0,46005 & 0,53817 & 0,36593 & 0,18846 & 0,04094 \\
\hline \multicolumn{2}{|l|}{ Mediana } & 0,45460 & 0,26196 & 0,18056 & 0,08813 & 0,02505 & 0,50347 & 0,60494 & 0,41564 & 0,20974 & 0,05015 \\
\hline
\end{tabular}

** Significativo a $1 \%$ de probabilidade.

DAE = Dias Após a Emergência da cultura da soja; $\mathrm{X}$ = quantidade de calda de corante FDC-1 + glyphosate depositada no solo $\left(\right.$ PL cm $\left.\mathrm{cm}^{-2}\right) ; \mathrm{A}, \mathrm{B}$ e C são as estimativas dos parâmetros do modelo.

deposição ao longo do tempo pode causar redução na eficiência, uma vez que, quanto maior a planta, menor será a disponibilidade de produto para fitointoxicação.

Os resultados encontrados coincidem com os obtidos por Souza (2002), o qual observou, em campo, que depósitos irregulares podem significar necessidade de aumento da dose para se atingir a mesma eficácia de controle, visto que, para as plantas daninhas localizadas mais próximas das linhas da cultura, o depósito da calda de pulverização pode ser desuniformizado. 
De forma geral, é possivel concluir neste trabalho que a deposição da solução traçante FDC-1 + glyphosate em amendoim-bravo foi inversamente proporcional ao seu desenvolvimento; entre o $27^{\circ}$ e $41^{\circ}$ dia após a emergência, as plantas localizadas próximas às linhas da cultura da soja receberam praticamente a metade do herbicida pulverizado, quando comparadas às localizadas na entrelinha. Essa informação sugere que maior garantia de eficiência pode ser conseguida através de aplicações precoces, com infestação no início do seu desenvolvimento.

O modelo de Gompertz ajustou-se adequadamente aos dados originais, apresentando elevado coeficiente de determinação para os alvos naturais e artificiais $\left(R^{2}\right.$ t 0,98 e 0,95$)$ e baixos valores de soma de quadrado de resíduos em todas as épocas de avaliação estudadas.

\section{LITERATURA CITADA}

BLANCO, H. G. et al. Observações sobre o período crítico em que a plantas daninhas competem com a soja (Glycine max (L.) Merrill). O Biológico, v. 39, n.2, p.31-35. 1973.

BLANCO, H.G. et al. Período crítico de competição de uma comunidade natural de mato em soja. In: SEMINÁRIO NACIONAL DE PESQUISA DE SOJA, 1., 1979, Londrina. Documentos ... Londrina: Embrapa Soja, 1979. p. 151-157.

CARVALHO, F.T.; VELINI, E. D. Períodos de interferência de plantas daninhas na cultura da soja I - Cultivar IAC 11. Planta Daninha, v. 19, n. 3, p. 317-322, 2001.

FURLANETTI, A. C. et al. Uniformidade de deposição da calda de pulverização de herbicidas em barra lateral protegida com diferentes combinações de pontas de pulverização. Planta Daninha, v. 19, n. 3, p. 445-456, 2001.

GAZZIERO, D. L. P.; FLECK, N. G. Efeitos de três herbicidas pós-emergentes aplicados em diferentes horas do dia sobre ervas daninhas e plantas de soja (Glycine max (L.) Merrill). Planta Daninha, v. 3, n. 1, p. 23-28, 1980.

GAZZIERO, D. L. P. et al. Avaliação da eficiência e seletividade do herbicida glyphosate aplicado na cultivar BR16RR. In: CONGRESSO BRASILEIRO DE SOJA, 1999, Londrina. Anais... Londrina: Embrapa Soja, 1998. p. 398.

GAZZIERO, D. L. P. et al. As plantas daninhas e a semeadura direta. Londrina: Embrapa Soja, 2001. 59 p. (Circular Técnica 33)

LIMA, P. R. F.; MACHADO-NETO, J. G. Otimização da aplicação de fluazifop-p-butil em pós-emergência na cultura da soja (Glycine max). Planta Daninha, v. 19, n. 1, p. 85-95, 2001.
MACIEL, C. D. G. et al. Deposição e distribuição de calda de pulverização em plantas de feijoeiro (Phaseolus vulgaris) e capim-brachiaria (Brachiaria decumbens). Planta Daninha, v. 19, n. 1, p. 103-110, 2001.

MACIEL, C. D. G. Simulação do caminhamento de herbicidas em diferentes tipos e quantidades de palhadas utilizadas no sistema de plantio direto. 2001. 89 p. Dissertação (Mestrado em Agronomia) - Universidade Estadual Paulista Júlio de Mesquita Filho, Botucatu, 2001.

MATUO, T. Fundamentos da tecnologia de aplicação de agrotóxicos. In: Tecnologia e segurança na aplicação de agrotóxicos: novas tecnologias, 2., 1998, Santa Maria. Departamento de Defesa Sanitária, Sociedade de Agronomia de Santa Maria, 1998. p. 95-1.

OZEKI, Y.; KUNZ, R. P. Tecnologia de aplicação aérea aspectos práticos. In: Tecnologia e segurança na aplicação de agrotóxicos: novas tecnologias, 2., 1998. Santa Maria. Departamento de Defesa Fitossanitária, Sociedade de Agronomia de Santa Maria, 1998. p. 65-78.

PALADINI, L. A. Metodologia para avaliação da deposição em pulverizações. 2000. $111 \mathrm{f}$. Tese (Doutorado em Agronomia) - Universidade Estadual Paulista Júlio de Mesquita Filho, Botucatu, 2000.

PITELLI, R. A. Interferência de plantas daninhas em culturas agrícolas. Inf. Agropec., v. 11, n. 129, p. 16-27, 1985.

PITELLI, R. A.; DURIGAN, J. C. Terminologia para períodos de controle e de convivência das plantas daninhas em culturas anuais e bianuais. In: CONGRESSO BRASILEIRO DE HERBICIDAS E PLANTAS DANINHAS, 15., 1984, Belo Horizonte. Resumos... Belo Horizonte: SBHED, 1984. p. 37-38.

RODRIGUES, B. N.; ALMEIDA, F. S. Guia de herbicidas. 4.ed. Londrina: 1998. 647 p.

SOUZA, R. T. Efeito da eletrização de gotas sobre a variabilidade dos depósitos de pulverização e eficácia do glyphosate no controle de plantas daninhas na cultura da soja. 2002. $69 \mathrm{f}$. Tese (Doutorado em Agronomia) Universidade Estadual Paulista Júlio de Mesquita Filho, Botucatu, 1997.

TOMAZELLA, M. S. Avaliação da deposição da calda de pulverização em função da densidade populacional de Brachiaria plantaginea (Link) wicth, volume e ângulo de aplicação. 1997. 78 f. Dissertação (Mestrado em Agronomia) - Universidade Estadual Paulista Júlio de Mesquita Filho, Botucatu, 1997.

VELINI, E. D. Estudos e desenvolvimento de métodos experimentais e amostrais adaptados à matologia. 1995. $250 \mathrm{f}$. Tese (Doutorado em Agronomia) - Universidade Estadual Paulista Julio de Mesquita Filho, Jaboticabal, 1995.

Planta Daninha, Viçosa-MG, v. 24, n. 1, p. 173-181, 2006 